\title{
Penanganan Ketidak Seimbangan Kelas Menggunakan Pendekatan Level Data
}

\author{
Abdurraghib Segaf Suweleh, Dyah Susilowati, Hairani, Khairan Marzuki
}

Universitas Bumigora, Indonesia

\section{Article Info}

Article history:

Received, 14 August 2020

Revised, 21 August 2020

Accepted, 11 September 2020

\section{Kata kunci:}

Ketidak Seimbangan Kelas Level Data

SMOTE

K-Means-SMOTE

Metode C4.5

\begin{abstract}
ABSTRAK
Setiap tahun bagian kemahasiswaan Universitas Bumigora melakukan seleksi mahasiswa yang berhak mendapatkan Beasiswa Peningkatan Prestasi Akademik (Beasiswa PPA). Dalam proses seleksi pemilihan penerima Beasiswa PPA terdapat permasalahan seperti kesulitan dalam menentukan mahasiswa yang berhak menerima beasiswa, dikarenakan jumlah kuota beasiswa lebih sedikit dibandingkan jumlah mahasiswa yang mendaftar beasiswa. Kumpulan data hasil seleksi Beasiswa PPA sebanyak 150 instance. Terdapat ketidak seimbangan kelas pada data yang digunakan yaitu 85 instance kelas tidak layak dan 65 instance kelas layak. Solusi yag ditawarkan adalah menggunakan pendekatan level data untuk menyeimbangkan kelasnya seperti metode SMOTE dan k-means-SMOTE. Adapun tujuan penelitian ini adalah menangani permasalahan ketidak seimbangan kelas pada data beasiswa PPA Universitas Bumigora menggunakan pendekatan level data untuk meningkatkan kinerja metode C4.5. Tahapan-tahapan penelitian ini terdiri dari pengumpulan data Beasiswa PPA, data preprocesing, klasifikasi, dan pengujian kinerja. Berdasarkan hasil pengujiannya, pendekatan level data menggunakan metode k-means-SMOTE dan metode C4.5 memiliki kinerja terbaik untuk klasifikasi penerima Beasiswa PPA dengan akurasi $81.3 \%$, sensitivitas $84.9 \%$, dan spesifisitas $77.6 \%$. Dengan demikian, metode k-meanSMOTE dan metode C4.5 memiliki kinerja terbaik berdasarkan akurasi, sensitivitas, dan spesifisitas.
\end{abstract}

\section{ABSTRACT}

Every year student affairs division of Bumigora University selects students who are entitled to receive PPA scholarships. In selection process for PPA scholarship recipients there are problems such as difficulties in determining which students are eligible to receive scholarships, because number of scholarship quotas is less than number of students applying for scholarships. The data collection resulted from PPA scholarship selection is 150 instances. There is a class imbalance in data used, namely 85 instances of mayority class and 65 instances of minority class. Solution offered is to use a data level approach to balance the class such as SMOTE and k-means-SMOTE methods. The purpose of this study is to address problem of class imbalance in PPA Bumigora University scholarship data using a data level approach to improve performance of C4.5 method. The stages of this research consisted of collecting PPA scholarship data, preprocessing data, classification, and performance testing. Based on test results, data level approach using k-meansSMOTE method and C4.5 method has the best performance for classification of PPA scholarship recipients with an accuracy of $81.3 \%$, sensitivity of $84.9 \%$, and specificity of $77.6 \%$. Thus, k-means-SMOTE method and C4.5 method have the best performance based on accuracy, sensitivity, and specificity.

This is an open access article under the CC BY-SA license.

\section{Penulis Korespondensi:}

Hairani,

Program Studi Ilmu Komputer,

Universitas Bumigora.

Email: hairani@universitasbumigora.ac.id 


\section{PENDAHULUAN}

Beasiswa Peningkatan Prestasi Akademik atau PPA merupakan beasiswa yang diberikan oleh pemerintah kepada mahasiswa yang memiliki prestasi dibidang akademik. Universitas Bumigora merupakan salah satu kampus swasta yang ikut berperan mendukung pemerintah dalam hal pemberian beasiswa PPA kepada mahasiswanya. Setiap tahun bagian kemahasiswaan melakukan seleksi mahasiswa yang berhak mendapatkan beasiswa PPA. Berdasakan hasil wawancara dengan Wakil Rektor 3 Universitas Bumigora terdapat permasalahan dalam proses seleksi pemilihan penerima beasiswa PPA seperti kesulitan menentukan mahasiswa yang berhak menerima beasiswa, dikarenakan jumlah kuota beasiswa lebih sedikit dibandingkan jumlah mahasiswa yang mendaftar beasiswa. Kumpulan data hasil seleksi beasiswa PPA yang dilakukan setiap tahunnya, hanya tersimpan pada komputer dan belum dimanfaatkan dengan maksimal. Padahal kumpulan data tersebut dapat dianalisis untuk mendapatkan pola-pola atau pengetahuan seperti kriteria mahasiswa yang mendapatkan beasiswa PPA atau tidak. Salah satu solusi yang ditawarkan pada penelitian ini adalah menggunakan konsep data mining. Data mining adalah sebuah cara untuk mengubah kumpulan-kumpulan data yang ada menjadi sebuah pengetahuan sehingga mendapatkan pola-pola tertentu. Salah satu task data mining adalah klasifikasi. Seleksi penerima beasiswa sudah banyak dilakukan penelitian sebelumnya dengan menggunakan berbagai metode data mining seperti metode C4.5 [1]]-[5], $k$-Nearest Neighbours (k-NN)[6][9], Bayesian MCMC [10], dan Nä̈ve Bayes [11].

Penelitian [3] menggunakan metode C4.5 untuk klasifikasi penerima beasiswa PPA. Kelemahan penelitian tersebut adalah tidak menyelesaikan permasalahan ketidakseimbangan kelas pada data beasiswa yang digunakan. Penelitian [11] untuk klasifikasi penerima beasiswa bidikmisi menggunakan metode Nä̈ve Bayes. Kelemahan penelitian tersebut, tidak menyelesaikan permasalahan ketidakseimbangan kelas pada data yang digunakan dan tidak hanya itu, penelitian tersebut menggunakan metode pengujian data splite dengan menentukan jumah data training dan data testing, hal tersebut akan berdampak pada hasil klasifikasi yang rawan terjadinya overfitting.

Penelitian [4] menggunakan metode C4.5 untuk klasifikasi penerima beasiswa bidikmisi serta hasil penelitiannya adalah metode $\mathrm{C} 4.5$ mendapatkan akurasi sebesar 79.8\%. Kelemahan penelitian tersebut, tidak menyelesaikan permasalahan ketidakseimbangan kelas pada data yang digunakan dan tidak hanya itu, penelitian tersebut menggunakan metode pengujian data splite dengan menentukan jumah data training dan data testing, hal tersebut akan berdampak pada hasil klasifikasi yang rawan terjadinya overfitting. Penelitian [5] menggunakan metode C4.5 untuk klasifikasi penerima beasiswa. Kelemahan penelitian tersebut, tidak menyelesaikan permasalahan ketidakseimbangan kelas pada data yang digunakan

Berdasarkan kajian penelitian sebelumnya, ada celah penelitian yang bisa dilakukan yaitu belum ada yang mengatasi permasalahan ketidakseimbangan kelas untuk klasifikasi penerima beasiswa. Ketidakseimbangan kelas merupakan jumlah antar kelas pada sebuah data tidak seimbang. Dengan adanya ketidakseimbangan kelas pada data penerima beasiswa dapat mengakibatkan metode klasifikasi cendrung mengklasifikasikan kelas tidak layak (kelas mayoritas) dibandingkan kelas layak (kelas minoritas).

Penelitian ini mengusulkan pendekatan level data seperti metode SMOTE [12] dan k-means-SMOTE [13] untuk menangani permasalahan ketidakseimbangan kelas pada data beasiswa PPA. Dengan mengatasi permasalahan ketidakseimbangan kelas pada data tersebut, dapat meningkatkan kinerja metode klasifikasi berdasarkan akurasi, sensitivitas, dan spesifisitas. Adapun metode klasifikasi yang digunakan penelitian ini adalah metode $\mathrm{C} 4.5$ dikarenakan memiliki kinerja yang baik untuk klasifikasi penerima beasiswa dan termasuk 10 metode paling banyak digunakan [14].

\section{METODE PENELITIAN}

Tahapan penelitian ini menggunakan tahapan data mining berdasarkan penelitian [13], [15]. Adapun tahapan penelitiannya terdiri dari pengumpulan data penerima beasiswa PPA Universitas Bumigora, data preprocessing, klasifikasi, dan pengujian kinerja menggunakan tabel confussion matrix. Adapun detail tahapan penelitian yang digunakan ditunjukkan pada Gambar 1. 


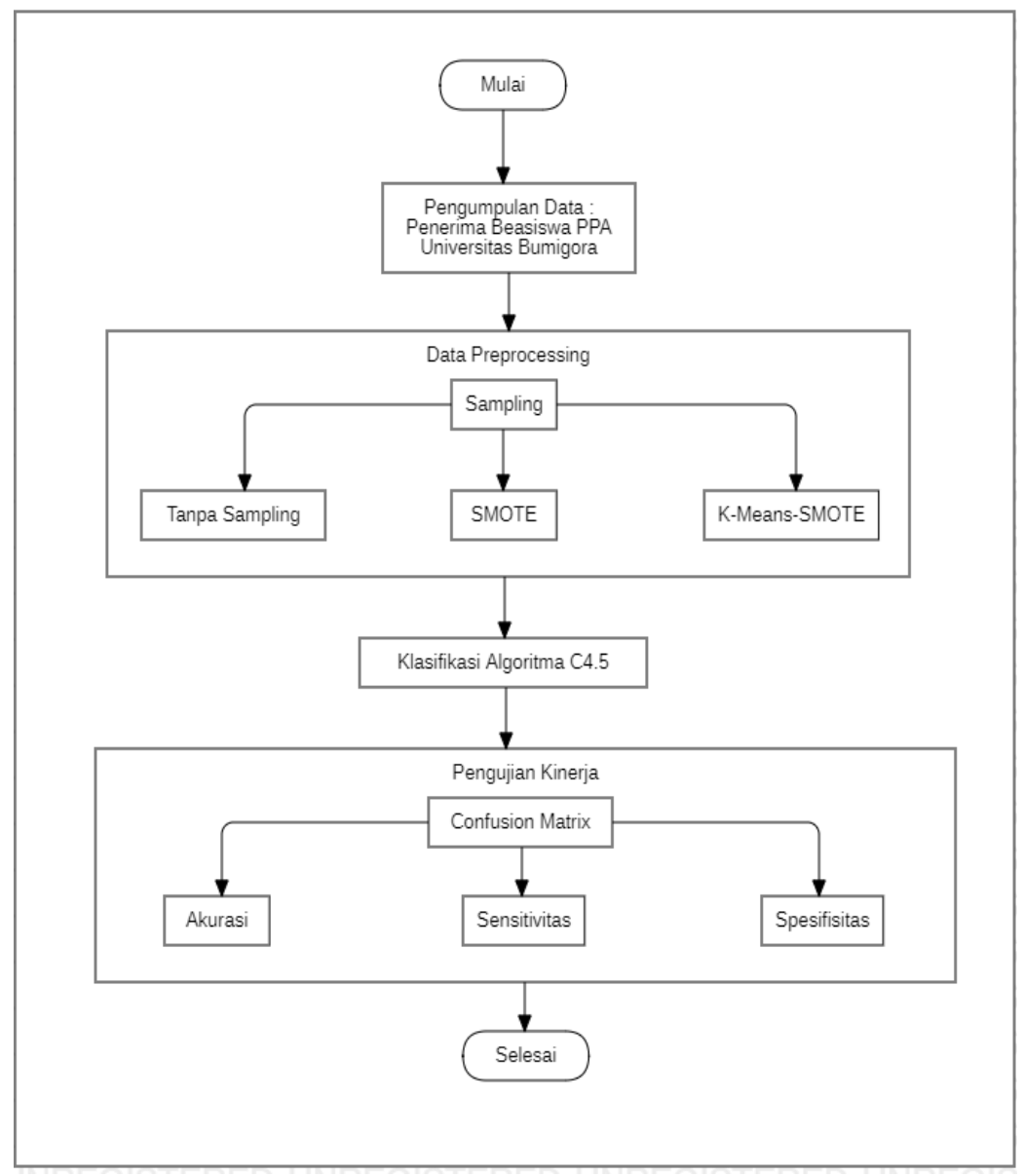

Gambar 1. Tahapan Penelitian Data Mining

Tahapan pertama dalam penelitian ini adalah proses pengumpulan dataset penerima beasiswa PPA Universitas Bumigora. Dataset tersebut terdiri dari 150 instance dan 5 atribut. Dari 150 instance terdiri dari 85 instance kelas tidak layak dan 65 instance kelas layak. Adapun detail atribut datasetnya dapat dilihat pada Tabel 1.

Tabel 1. Atribut Data Beasiswa PPA Universitas Bumigora

\begin{tabular}{ccl}
\hline No & Atribut & \multicolumn{1}{c}{ Keterangan } \\
\hline 1 & Jumlah SKS & Jumlah SKS diambil pelamar pada saat proses seleksi \\
2 & Jumlah Tanggungan & Jumlah tanggungan orang tua \\
3 & IPK & Indeks prestasi kumulatif \\
4 & Penghasilan & Penghasilan orang tua \\
5 & Keputusan (Kelas) & Hasil keputusan beasiswa \\
\hline
\end{tabular}

Tahapan kedua adalah data preprocessing. Pada tahapan ini dilakukan sampling data pada dataset yang digunakan, karena terdapat ketidakseimbangan kelas antara kelas tidak layak (kelas mayoritas) dan 65 kelas layak (kelas minoritas). Penelitian ini mengusulkan menggunakan metode SMOTE dan k-means-SMOTE.

Tahapan ketiga adalah melakukan klasifikasi menggunakan algoritma C4.5. Validasi model metode klasifikasi yang digunakan pada penelitian ini adalah 10-fold cross validation. Metode 10-fold cross validation membagi dataset menjadi 10 kelompok data.

\section{1. $\quad$ Metode $\mathbf{C} 4.5$}

Metode klasifikasi penelitian ini menggunakan metode C4.5. Metode C4.5 salah satu metode klasifikasi dalam data mining. Tahapan-tahapan metode C4.5 dalam pembuatan pohon keputusan seperti berikut [16]:

1. Mempersiapkan data latih

2. Perhitungan nilai entropy dengan persamaan (4)

$$
\operatorname{Entropy}(S)=\sum_{i=1}^{n}-\text { pi. } \log _{2} \text { pi }
$$


3. Perhitungan nilai gain dengan persamaan (5)

$$
\operatorname{Gain}(S, A)=\operatorname{Entropy}(S)-\sum_{i=1}^{n} \frac{\left|S_{i}\right|}{S} * \operatorname{Entropy}\left(S_{i}\right)
$$

4. Mengulangi step 2 sampai seluruh record terpartisi.

Tahapan terakhir penelitian ini adalah pengujian kinerja dari algoritma C4.5 dalam mengklasifikasikan penerima beasiswa PPA menggunakan tabel confusion matrix. Metode confusion matrix menguji 3 hal yaitu akurasi (1), sensitivitas (2), dan spesifisitas (3). Tabel confusion matriks dapat dilihat pada Tabel 3.

Tabel 2. Confussion Matrix

\begin{tabular}{ccc}
\hline \multirow{2}{*}{ Kelas Aktual } & \multicolumn{2}{c}{ Kelas Prediksi } \\
\cline { 2 - 3 } & $\begin{array}{c}\text { Tidak Layak } \\
\text { (Kelas Mayoritas) }\end{array}$ & $\begin{array}{c}\text { Layak } \\
\text { (Kelas Minoritas) }\end{array}$ \\
\hline Tidak Layak & True Negative $(\mathrm{TN})$ & False Positive (FP) \\
Layak & False Negative $(\mathrm{FN})$ & True Positive (TP) \\
\hline
\end{tabular}

Rumus yang digunakan dalam perhitungan akurasi (1), sensitivitas (2), dan spesifisitas (3) sebagai berikut:

$$
\begin{aligned}
& \text { Akurasi }=\frac{T P+T N}{T P+F N+T N+F P} \\
& \text { Sensitivitas }(\text { Recall })=\frac{T P}{T P+F N} \\
& \text { Spesifisitas }=\frac{T N}{T N+F P}
\end{aligned}
$$

True Positive (TP) merupakan kelas layak diprediksi secara benar. False Positive ( FP) merupakan kelas tidak layak diprediksi salah. True Negative (TN) merupakan kelas tidak layak diprediksi secara benar. Sedangkan False Negative (FN) merupakan kelas layak diprediksi salah.

\section{HASIL DAN ANALISIS}

\subsection{Pengumpulan Data}

Data penerima beasiswa PPA Universitas Bumigora diperoleh dari bagian kemahasiswaan yaitu wakil rektor 3. Adapun rentang data beasiswa PPA yang digunakan adalah tahun 2015 - 2018. Jumlah data seleksi beasiswa PPA sebanyak 150 instance, terdiri dari 85 instance kelas tidak layak dan 65 instance kelas layak. Adapun contoh datanya ditunjukkan pada Tabel 3.

Tabel 3. Contoh Data Seleksi Beasiswa PPA

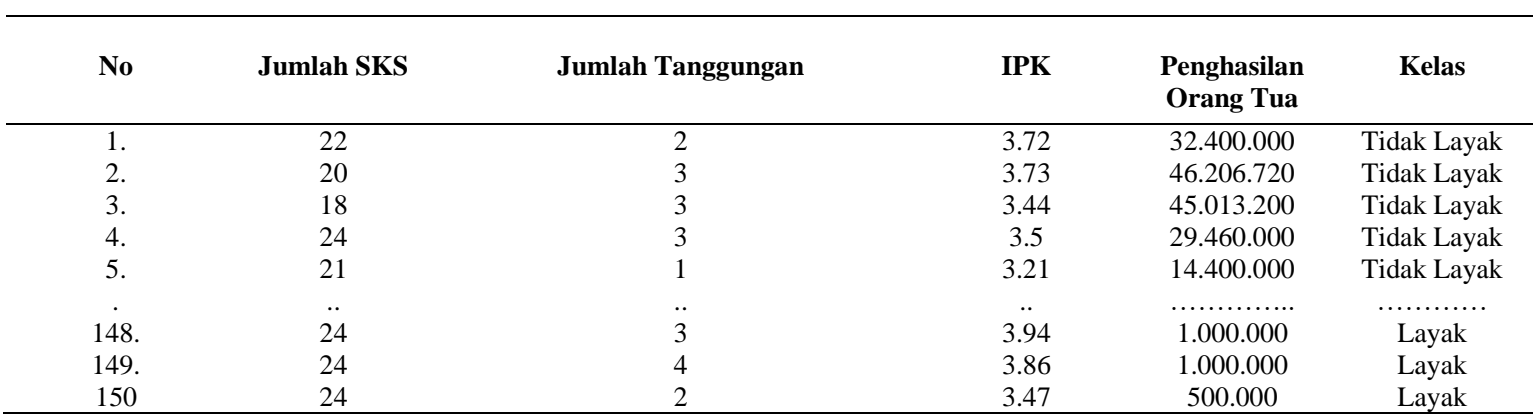

\subsection{Data Preprocessing}

Pada tahapan ini dilakukan sampling data pada dataset yang digunakan, karena terdapat ketidakseimbangan kelas antara kelas tidak layak (kelas mayoritas) dan kelas layak (kelas minoritas), hal tersebut akan berdampak pada metode C4.5 yang lebih condong mengklasifikasikan kelas tidak layak dibandingkan kelas layak. Untuk mengatasi permasalahan keridakseimbangan kelas pada data beasiswa PPA Universitas Bumigora, penelitian ini mengusulkan menggunakan metode SMOTE dan k-means-SMOTE. Adapun rasio kelas dataset dapat dilihat pada Tabel 3. 
Tabel 4. Rasio Kelas Data Beasiswa PPA Universitas Bumigora

\begin{tabular}{cccc}
\hline \multirow{2}{*}{ No } & Metode samplig & \multicolumn{2}{c}{ Jumlah Instance } \\
\cline { 3 - 4 } & Original & $\begin{array}{c}\text { Tidak Layak } \\
\text { (Kelas Mayoritas) }\end{array}$ & $\begin{array}{c}\text { Layak } \\
\text { (Kelas Minoritas) }\end{array}$ \\
\hline 1 & SMOTE & 85 & 65 \\
2 & k-means-SMOTE & 85 & 85 \\
3 & 86 & 85 \\
\hline
\end{tabular}

\subsection{Metode Klasifikasi}

Metode klasifikasi penelitian ini menggunakan metode C4.5. Adapun tahapan-tahapan perhitungan metode C4.5 seperti berikut:

1. Mempersiapkan data latih. Misalnya dicontohkan data training dan data testing pada Tabel 4.

Tabel 5. Data Latih

\begin{tabular}{ccccc}
\hline Jumlah SKS & Jumlah Tanggungan & IPK & $\begin{array}{c}\text { Penghasilan } \\
\text { Orang Tua }\end{array}$ & Kelas \\
\hline 22 & 2 & 3.72 & 32.400 .000 & Tidak Layak \\
20 & 3 & 3.73 & 46.206 .720 & Tidak Layak \\
18 & 3 & 3.44 & 45.013 .200 & Tidak Layak \\
24 & 3 & 3.5 & 29.460 .000 & Tidak Layak \\
21 & 1 & 3.21 & 14.400 .000 & Tidak Layak \\
24 & 2 & 3.53 & 750.000 & Layak \\
24 & 3 & 3.94 & 1.000 .000 & Layak \\
24 & 4 & 3.86 & 1.000 .000 & Layak \\
24 & 2 & 3.47 & 500.000 & Layak \\
\hline
\end{tabular}

Sebelum melakukan perhitungan entropy dan gain, terlebih dahulu dikonversi instance bersifat kontinu pada atribut jumlah sks, jumlah tanggungan, IPK, dan penghasilan orang tua. Adapun hasil konversi atributnya ditunjukkan pada Tabel 5, Tabel 6, Tabel 7, dan Tabel 8.

Tabel 6. Hasil Konversi Atribut Jumlah SKS

\begin{tabular}{cc}
\hline Sebelum Konversi & Sesudah Konversi \\
\hline $23-24$ & Banyak \\
$21-22$ & Cukup \\
$\leq 20$ & Sedikit \\
\hline
\end{tabular}

Tabel 7. Hasil Konversi Atribut Jumlah Tanggungan

\begin{tabular}{cc}
\hline Sebelum Konversi & Sesudah Konversi \\
\hline$\geq 5$ & Banyak \\
$3-4$ & Sedang \\
$1-2$ & Sedikit \\
\hline
\end{tabular}

Tabel 8. Hasil Konversi Atribut IPK

\begin{tabular}{cc}
\hline Sebelum Konversi & Sesudah Konversi \\
\hline $2.00-2.75$ & Memuaskan \\
$2.76-3.50$ & Sangat Memuaskan \\
$3.51-4.00$ & Dengan Pujian \\
\hline
\end{tabular}

Tabel 9. Hasil Konversi Atribut Penghasilan Orang Tua

\begin{tabular}{cc}
\hline Sebelum Konversi & Sesudah Konversi \\
\hline$\geq 5.000 .000$ & Besar \\
$2.500 .000-4.999 .999$ & Sedang \\
$1.000 .000-2.499 .000$ & Cukup \\
$<1.000 .000$ & Kecil \\
\hline
\end{tabular}


2. Menghitung nilai entropy dengan persamaan (4)

$$
\begin{aligned}
& \text { Entropy(Total) }=\left(-\left(\frac{5}{9}\right) *\left(\log _{2}\left(\frac{5}{9}\right)\right)\right)+\left(-\left(\frac{4}{9}\right) *\left(\log _{2}\left(\frac{4}{9}\right)\right)\right)=0.99107 \\
& \text { Entropy(Jumlah SKS - Banyak })=\left(-\left(\frac{1}{5}\right) *\left(\log _{2}\left(\frac{1}{5}\right)\right)\right)+\left(-\left(\frac{4}{5}\right) *\left(\log _{2}\left(\frac{4}{5}\right)\right)\right)=0.72193 \\
& \text { Entropy(Jumlah SKS - Cukup) }=\left(-\left(\frac{2}{2}\right) *\left(\log _{2}\left(\frac{2}{2}\right)\right)\right)+\left(-\left(\frac{0}{2}\right) *\left(\log _{2}\left(\frac{0}{2}\right)\right)\right)=0 \\
& \text { Entropy(Jumlah SKS - Sedikit) }=\left(-\left(\frac{2}{2}\right) *\left(\log _{2}\left(\frac{2}{2}\right)\right)\right)+\left(-\left(\frac{0}{2}\right) *\left(\log _{2}\left(\frac{0}{2}\right)\right)\right)=0 \\
& \text { Entropy(JumlahTanggungan-Banyak) }=\left(-\left(\frac{0}{0}\right) *\left(\log _{2}\left(\frac{0}{0}\right)\right)\right)+\left(-\left(\frac{0}{0}\right) *\left(\log _{2}\left(\frac{0}{0}\right)\right)\right)=0 \\
& \text { Entropy(Jumlah Tanggungan-Sedang })=\left(-\left(\frac{3}{5}\right) *\left(\log _{2}\left(\frac{3}{5}\right)\right)\right)+\left(-\left(\frac{2}{5}\right) *\left(\log _{2}\left(\frac{2}{5}\right)\right)\right)=0.97095 \\
& \text { Entropy(Jumlah Tanggungan-Sedikit) }=\left(-\left(\frac{2}{4}\right) *\left(\log _{2}\left(\frac{2}{4}\right)\right)\right)+\left(-\left(\frac{2}{4}\right) *\left(\log _{2}\left(\frac{2}{4}\right)\right)\right)=1
\end{aligned}
$$

\begin{tabular}{|c|c|c|c|c|c|c|}
\hline Atribut & Kelas & Jumlah Kasus (S) & Tidak Layak & Layak & Entropy & Gain \\
\hline Total & & 9 & 5 & 4 & 0.99107 & \multirow[b]{2}{*}{0.59} \\
\hline Jumlah SKS & $\begin{array}{l}\text { Banyak } \\
\text { Cukup } \\
\text { Sedikit }\end{array}$ & $\begin{array}{l}5 \\
2 \\
2\end{array}$ & $\begin{array}{l}1 \\
2 \\
2\end{array}$ & $\begin{array}{l}4 \\
0 \\
0\end{array}$ & $\begin{array}{c}0.72192 \\
0 \\
0\end{array}$ & \\
\hline $\begin{array}{c}\text { Jumlah } \\
\text { Tanggungan }\end{array}$ & $\begin{array}{l}\text { Banyak } \\
\text { Sedang } \\
\text { Sedikit }\end{array}$ & $\begin{array}{l}0 \\
5 \\
4\end{array}$ & $\begin{array}{l}0 \\
3 \\
2\end{array}$ & $\begin{array}{l}0 \\
2 \\
2\end{array}$ & $\begin{array}{c}0 \\
0.97095 \\
1\end{array}$ & 0.00721 \\
\hline IPK & $\begin{array}{c}\text { Dengan Pujian } \\
\text { Sangat Memuaskan } \\
\text { Memuaskan }\end{array}$ & $\begin{array}{l}5 \\
4 \\
0\end{array}$ & $\begin{array}{l}2 \\
3 \\
0\end{array}$ & $\begin{array}{l}3 \\
1 \\
0\end{array}$ & $\begin{array}{c}0.97095 \\
0.81127 \\
0\end{array}$ & 0.09109 \\
\hline $\begin{array}{c}\text { Penghasilan } \\
\text { Orangtua }\end{array}$ & $\begin{array}{l}\text { Besar } \\
\text { Sedang } \\
\text { Cukup } \\
\text { Kecil }\end{array}$ & $\begin{array}{l}5 \\
0 \\
2 \\
2\end{array}$ & $\begin{array}{l}5 \\
0 \\
0 \\
0\end{array}$ & $\begin{array}{l}0 \\
0 \\
2 \\
2\end{array}$ & $\begin{array}{l}0 \\
0 \\
0 \\
0\end{array}$ & 0.99107 \\
\hline
\end{tabular}

3. Menghitung nilai entropy dengan persamaan (5)

$$
\begin{aligned}
& \text { Gain }(\text { Jumlah SKS })=0.99107-\left(\left(\frac{5}{9}\right) * 0.72192\right)+\left(\left(\frac{2}{9}\right) * 0\right)+\left(\left(\frac{2}{9}\right) * 0\right)=0.59 \\
& \text { Gain }(\text { Jumlah Tanggungan })=0.99107-\left(\left(\frac{0}{9}\right) * 0\right)+\left(\left(\frac{5}{9}\right) * 0.97095\right)+\left(\left(\frac{4}{9}\right) * 1\right)=0.00721
\end{aligned}
$$

Adapun hasil perhitungan entropy dan gain ditunjukkan pada Tabel 9.

Tabel 10. Hasil Perhitungan Entropy dan Gain pada Node 1

\subsection{Pengujian Kinerja}

Pengujian kinerja dilakukan untuk mengetahui seberapa baik tingkat akurasi, sensitivitas, dan spesifisitas menggunakan tabel confusion matrix. Metode validasi pengujiannya menggunakan 10-fold cross validation dengan membagi data sebanyak 10 kelompok. Adapun hasil pengujiannya ditunjukkan pada Tabel 10 dan Tabel 11. 
Tabel 11. Confusion Matrix Metode C4.5

\begin{tabular}{ccccc}
\hline \multirow{2}{*}{ Metode sampling } & Aktual & Tidak Layak & Prediksi & \multirow{2}{*}{ Layak } \\
\cline { 3 - 4 } & & & 20 & \\
\hline \multirow{3}{*}{ Tanpa Sampling } & Tidak Layak & 65 & 51 & $76.5 \%$ \\
& Layak & 14 & $71.8 \%$ & $78.5 \%$ \\
& Recall Kelas & $82.3 \%$ & 20 & $76.5 \%$ \\
SMOTE & Tidak Layak & 65 & 70 & $82.4 \%$ \\
& Layak & 15 & $77.8 \%$ & $77.6 \%$ \\
& Recall Kelas & $81.3 \%$ & 19 & $84.9 \%$ \\
& Tidak Layak & 66 & 73 & \\
\hline \multirow{3}{*}{ k-means-SMOTE } & Layak & 13 & $79.3 \%$ & \\
& Recall Kelas & $83.5 \%$ & & \\
\hline
\end{tabular}

$$
\begin{gathered}
\text { Akurasi }=\frac{73+66}{73+19+66+13}=\frac{139}{171}=81.3 \% \\
\text { Sensitivitas }=\frac{73}{73+13}=\frac{73}{86}=84.9 \% \\
\text { Spesifisitas }=\frac{66}{66+19}=\frac{66}{85}=77.6 \%
\end{gathered}
$$

Tabel 12. Perbandingan Kinerja Metode Sampling pada C4.5

\begin{tabular}{cccc}
\hline \multirow{2}{*}{ Metode sampling } & \multicolumn{3}{c}{ Kinerja } \\
\cline { 2 - 4 } & Akurasi & Sensitivitas & Spesifisitas \\
\hline Original & $77.3 \%$ & $78.5 \%$ & $76.5 \%$ \\
SMOTE & $79.4 \%$ & $82.4 \%$ & $76.5 \%$ \\
k-means-SMOTE & $\mathbf{8 1 . 3 \%}$ & $\mathbf{8 4 . 9 \%}$ & $\mathbf{7 7 . 6 \%}$ \\
\hline
\end{tabular}

Berdasarkan Tabel 11, metode k-means-SMOTE memiliki kinerja terbaik berdasarkan akurasi, sensitivitas, dan spesifisitas dibandingkan menggunakan SMOTE dan tanpa sampling. Metode k-means-SMOTE memiliki kinerja terbaik, dikarenakan terlebih dahulu melakukan pengelompokan pada kelas mayoritas dan minoritas. Jika pada pengelompokkan kelas minoritas terdapat rasio ketidakseimbangan lebih dari 1, maka dilakukan penambahan data pada kelas minoritas menggunakan metode SMOTE [13], [17].

\section{KESIMPULAN}

Penggunaan pendekatan level data seperti metode SMOTE dan k-means-SMOTE untuk menyelesaikan permasalahan ketidakseimbangan kelas pada data beasiswa PPA dapat meningkatkan kinerja metode C4.5 seperti akurasi, sensitivitas, dan spesifisitas. Adapun kinerja terbaik dihasilkan dari kombinasi metode C4.5 dan k-means-SMOTE dibandingkan metode SMOTE dengan selisih $1.99 \%$ untuk akurasi, $2.5 \%$ untuk sensitivitas, dan $1.1 \%$ untuk spesifisitas. Dengan demikian, penggunaan pendekatan level data (k-meansSMOTE) dan metode klasifikasi C4.5 dapat digunakan untuk menentukan calon penerima beasiswa PPA Universitas Bumigora, karena memiliki kinerja yang baik berdasarkan akurasi, sensitivitas, dan spesifisitas. Untuk penelitian selanjutnya dapat menggunakan pendekatan hibrid yaitu menggabungkan level data (SMOTE dan k-means-SMOTE) dengan ensemble learning seperti boosting, bagging untuk meningkatkan kinerja metode klasifikasi C4.5.

\section{UCAPAN TERIMA KASIH}

Penulis mencucapkan banyak terimakasih kepada kampus universitas Bumigora yang telah mendukung dalam pemberian data calon penerima Beasiswa Mahasiswa, dan teman-teman dosen dan mahsiswa di lingkungan kampus Universitas Bumigora

\section{REFERENSI}

[1] Rismayanti, "Implementasi Algoritma C4.5 Untuk Menentukan Penerima Beasiswa di STT Harapan Medan," Media Infotama, vol. 12, no. 2, pp. 116-120, 2016.

[2] J. H. Jaman and N. I. P. Astuti, "Melakukan observasi ke tempat yang akan di teliti ( SDN Karawang Kulon," Techno Xplore, vol. 3, no. 1, pp. 25-29, 2018.

[3] A. S. Suweleh, D. Susilowati, and H. Hairani, "Aplikasi Penentuan Penerima Beasiswa Menggunakan Algoritma C4.5," Jurnal BITe, vol. 2, no. 1, pp. 12-21, 2020.

[4] M. S. Juliardi, R. Saptono, and D. E. Cahyani, "Universitas Sebelas Maret Bidikmisi Applicant's Classification using C4. 5 Algorithm," ITSMART: Jurnal Teknologi dan Informasi, vol. 6, no. 1, pp. 
16-23, 2017.

[5] N. Hijriana and M. Rasyidan, "Penerapan Metode Decision Tree Algoritma C4.5 untuk Seleksi Calon Penerima Beasiswa Tingkat Universitas," Sains Dan Teknologi, vol. 3, pp. 9-13, 2017.

[6] D. Noviana, Y. Susanti, and I. Susanto, "Analisis Rekomendasi Penerima Beasiswa Menggunakan Algoritma K-Nearest Neighbor (K-Nn) Dan Algoritma C4.5," Seminar Nasional Penelitian Pendidikan Matematika (SNP2M) 2019 UMT, pp. 79-87, 2019.

[7] Okfalisa, R. Fitriani, and Y. Vitriani, "The Comparison of Linear Regression Method and K-Nearest Neighbors in Scholarship Recipient," in 2018 19th IEEE/ACIS International Conference on Software Engineering, Artificial Intelligence, Networking and Parallel/Distributed Computing (SNPD), 2018, pp. 194-199.

[8] D. Kurniadi, E. Abdurachman, H. L. H. S. Warnars, and W. Suparta, "The prediction of scholarship recipients in higher education using k-Nearest neighbor algorithm," in IOP Conference Series: Materials Science and Engineering, 2018, pp. 1-7.

[9] N. Z. Dina and R. S. Marjianto, "Prediksi Penentuan Penerima Besasiswa Dengan Metode Knearest Neighbour," in Jurnal Nasional Informatika dan Teknologi Jaringan, 2018, vol. 2, no. 2, pp. 135-139.

[10] W. Suryaningtyas, N. Iriawan, K. Fithriasari, B. S. S. Ulama, I. Susanto, and A. A. Pravitasari, "On the Bernoulli Mixture Model for Bidikmisi Scholarship Classification with Bayesian MCMC," in IOP Conf. Series: Journal of Physics: Conf. Series 1090, 2018, vol. 1090, no. 1, pp. 1-8.

[11] H. Sulistiani and Y. T. Utami, "Penerapan Algoritma Klasifikasi sebagai Pendukung Keputusan Pemberian Beasiswa Mahasiswa," in SNTI VI-2018 Universitas Trisakti, 2018, pp. 300-305.

[12] Hairani, Setiawan, N. Akhmad, Adji, and T. Bharata, "Metode Klasifikasi Data Mining dan Teknik Sampling SMOTE Menangani Class Imbalance Untuk Segmentasi Customer pada Industri Perbankan," in Prosiding SNST Fakultas Teknik, 2016, vol. 1, no. 1, pp. 168-172.

[13] H. Hairani, K. E. Saputro, and S. Fadli, "K-means-SMOTE untuk menangani ketidakseimbangan kelas dalam klasifikasi penyakit diabetes dengan C4.5, SVM, dan naive Bayes," Jurnal Teknologi dan Sistem Komputer, vol. 8, no. 2, pp. 89-93, 2020.

[14] X. Wu et al., "Top 10 algorithms in data mining," Knowledge and information systems, vol. 14, no. 1, pp. 1-37, 2008 .

[15] Hairani and M. Innuddin, "Kombinasi Metode Correlated Naive Bayes dan Metode Seleksi Fitur Wrapper untuk Klasifikasi Data Kesehatan,” Jurnal Teknik Elektro, vol. 11, no. 2, pp. 50-55, 2019.

[16] L. Nurellisa et al., "Analisis Rekomendasi Calon Debitur Motor pada PT. XYZ Menggunakan Algoritma C4.5," Jurnal Teknologi Informasi dan Ilmu Komputer, vol. 7, no. 4, pp. 673-682, 2020.

[17] G. Douzas, F. Bacao, and F. Last, "Improving imbalanced learning through a heuristic oversampling method based on k-means and SMOTE," Information Sciences, vol. 465, pp. 1-20, 2018. 